\title{
Erratum to: Comparing Three Augmentative and Alternative Communication Modes for Children with Developmental Disabilities
}

\section{Larah van der Meer • Robert Didden • \\ Dean Sutherland • Mark F. O'Reilly • \\ Giulio E. Lancioni • Jeff Sigafoos}

\section{Erratum to: J Dev Phys Disabil (2012) 24:451-468}

DOI 10.1007/s10882-012-9283-3

In the original published version, Fig. 1 image is incorrect. The correct image is shown below:

The online version of the original article can be found at http://dx.doi.org/10.1007/s10882-012-9283-3.

L. van der Meer · J. Sigafoos

Victoria University of Wellington, Wellington, New Zealand

R. Didden

Radboud University Nijmegen, Nijmegen, The Netherlands

D. Sutherland

University of Canterbury, Christchurch, New Zealand

M. F. O’Reilly

The Meadows Center for the Prevention of Educational Risk, University of Texas at Austin, Austin, TX, USA

G. E. Lancioni

University of Bari, Bari, Italy

L. van der Meer $(\bowtie)$

School of Educational Psychology and Pedagogy, Victoria University of Wellington, PO Box 17-310, Karori, 6147 Wellington, New Zealand

e-mail: larah.vandermeer@vuw.ac.nz 


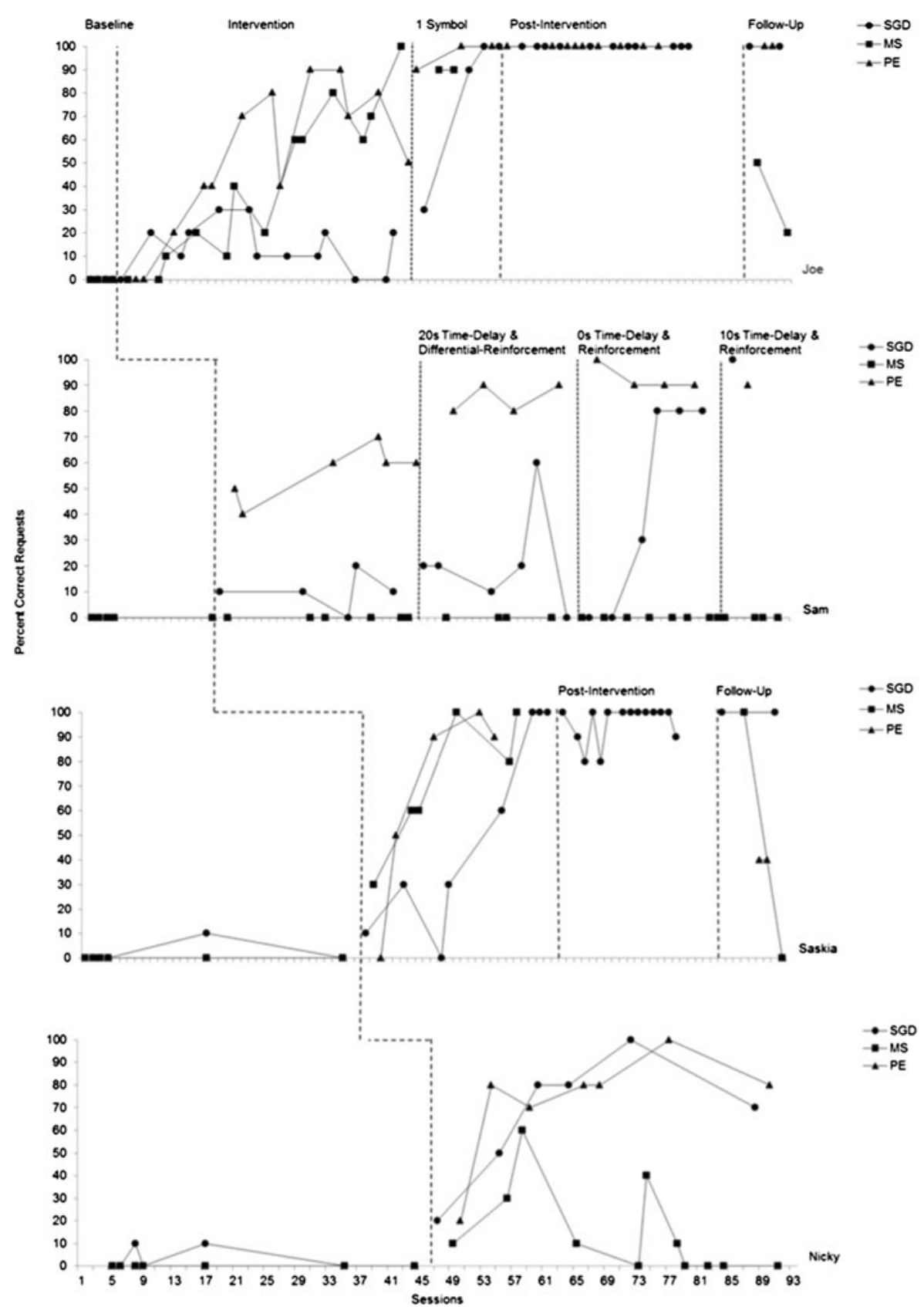

Fig. 1 Percentage of corrects requests using the SGD, PE, and MS options across sessions for each participant 